CHAPTER 18

\title{
THE NEURAL BASIS OF SEMANTIC AND EPISODIC FORMS OF SELF-KNOWLEDGE: Insights from Functional Neuroimaging
}

\author{
Arnaud D'Argembeau ${ }^{*, 1}$ and Eric Salmon ${ }^{2}$ \\ ${ }^{1}$ Department of Cognitive Sciences, University of Liège, Liège, Belgium; ${ }^{2}$ Cyclotron Research Centre, University of \\ Liège, Liège, Belgium \\ *Corresponding Author: Arnaud D’Argembeau_Email: a.dargembeau@ulg.ac.be
}

\begin{abstract}
Throughout evolution, hominids have developed greater capacity to think about themselves in abstract and symbolic ways. This process has reached its apex in humans with the construction of a concept of self as a distinct entity with a personal history. This chapter provides a review of recent functional neuroimaging studies that have investigated the neural correlates of such "higher-level" aspects of the human self, focusing in particular on processes that allow individuals to consciously represent and reflect on their own personal attributes (semantic forms of self-knowledge) and experiences (episodic forms of self-knowledge). These studies point to the medial prefrontal cortex (MPFC) as a key neural structure for processing various kinds of self-referential information. We speculate that the MPFC may mediate dynamic processes that appraise and code the self-relatedness or self-relevance of information. This brain region may thus play a key role in creating the mental model of the self that is displayed in our mind at a given moment.
\end{abstract}

Sensing in Nature, edited by Carlos López-Larrea.

C) 2012 Landes Bioscience and Springer Science+Business Media. 


\section{INTRODUCTION}

One great splitting of the whole universe into two halves is made by each of us; and for each of us almost all of the interest attaches to one of the halves; but we all draw the line of division between them in a different place. —William James, 1890, p. 289

The great splitting William James refers to is the division of the world into "me" and "not-me". ${ }^{1}$ Such division between self and nonself is implemented in many systems, at various levels of complexity; simple living organisms and even some robots, ${ }^{2}$ have some sort of self-models that allow them to distinguish between themselves and the external environment. Yet, among all known systems, it is undoubtedly in human beings that the sense of self has reached the highest level of refinement. The human sense of self comprises multiple facets or levels, from the consciousness of oneself as an agent and immediate subject of experience to the construction of a concept of oneself as a distinct entity with a personal history. ${ }^{3-6}$ Although a complete understanding of the brain mechanisms that support these multiple dimensions of self is still currently out of reach, research in social cognitive neuroscience ${ }^{7}$ has made important progress in identifying the brain regions that are involved in representing and reflecting on different types of self-referential information.

In this chapter, we review recent studies that have used functional neuroimaging techniques such as functional magnetic resonance imaging (fMRI) and positron emission tomography (PET) to investigate the neural correlates of "higher-level" self-referential processes. By higher-level self-referential processes, we mean processes that allow an organism to consciously represent and reflect on its own attributes and experiences, what Damasio has called the "autobiographical self". ${ }^{5}$ We address more specifically functional neuroimaging studies that have investigated the neural basis of semantic and episodic forms of self-knowledge. Our aim is not to provide an exhaustive review of all existing studies but rather to illustrate how functional neuroimaging has helped to better understand the brain mechanisms that contribute to creating the self/nonself distinction that William James referred to. It will be suggested, in particular, that the medial prefrontal cortex $(\mathrm{MPFC})^{\mathrm{a}}$ may play a key role in implementing this process.

\section{REPRESENTING ONE'S PERSONAL CHARACTERISTICS: SEMANTIC FORMS OF SELF-KNOWLEDGE}

In comparison with simpler, unreflective forms of self-awareness, the ability to think about oneself in abstract and symbolic ways is thought to have emerged late in evolution (perhaps in the Middle-Upper Paleolithic transition, between 40,000

\footnotetext{
${ }^{a}$ In this chapter, we use MPFC as a broad term to refer to the medial portion of the superior frontal gyrus, orbitofrontal gyrus and rostral anterior cingulate cortex (Brodmann's areas 9, 10, 11 and 32). We use this general term because in many studies of self-referential processing, activations along the medial part of the prefrontal cortex is quite extensive, encompassing several anatomically distinct subregions. It is likely, however, that different subregions within the MPFC support distinct functions in relation to self-referential processing (see ref. 8), though this issue remains to be investigated in detail.
} 
and 60,000 years ago, where we find instances of technological advances, art, body adornment and ritualistic burial) and it may be specifically human. ${ }^{9}$ Humans are able to consciously represent and reflect on their own personal attributes, such as their abilities and skills (e.g., "I can play guitar"), social roles (e.g., "I am a father"), psychological characteristics (e.g., "I am a shy person") and preferences (e.g., "I like red wine"). This collection of information about ourselves (which is not necessarily accurate) constitutes the self-concept, a complex knowledge structure stored in long-term memory that includes abstract, summary representations of our own personal characteristics. ${ }^{10}$ Those self-representations are semantic in nature in the sense that they have been abstracted from multiple experiences and can be accessed without the need to remember any specific past event. ${ }^{11,12}$

The experimental paradigm that has been most frequently used to study the neural correlates of semantic self-knowledge consists of asking participants to represent and reflect on their own psychological traits. Kelley et al, for example, measured brain activity using fMRI while participants made different types of judgments on trait adjectives (e.g., polite, dependable, daring, talkative). ${ }^{13}$ In one condition, participants had to judge whether or not the adjectives described their own psychological traits (self condition), whereas in a second condition they had to judge whether or not the adjectives described the traits of George W. Bush (other condition). In a third condition, participants performed a shallow processing task consisting of judging whether the adjectives were printed in uppercase letters (case condition). The results showed that the two semantic judgments (i.e., the self and other conditions) were associated with greater activity in the left inferior frontal cortex and the anterior cingulate cortex relative to nonsemantic judgments (i.e., the case condition). More interestingly, there were also differences in activations between the two types of semantic judgments, with judgments about the self leading to greater activation in the MPFC than judgments about the other. An increased activation in the MPFC when reflecting on one's own traits (compared to the traits of others or to making semantic judgments) has also been observed in several subsequent studies ${ }^{14-26}$ (see Fig. 1 for an illustration of the MPFC activations detected in different studies).

In functional brain imaging studies, successful assignment of a specific cognitive process to the detected brain activation depends on the appropriate contrasting of task conditions. Because early studies of self-referential processing used a public figure rather than a personally well-known person for the comparison condition, it has been argued that the brain activations observed when making judgments about the self versus others may reflect differences in the amount and complexity of retrieved knowledge and/or differences in affective response rather than the self versus other distinction per se. ${ }^{27}$ To address this issue, Heatherton et $\mathrm{al}^{28}$ used a similar task as Kelley et $\mathrm{al}^{13}$ but the other-referential condition involved a personally familiar other (i.e., one's best friend) rather than a public figure. They found that the same MPFC region previously identified as more activated when thinking about the self versus a nonclose other was also more activated when thinking about the self versus an intimate other. Similar results have been obtained in most reports, ${ }^{15,29,30}$ although some studies failed to detect differential activity in the MPFC when contrasting judgments referring to the self with judgments referring to a close other. ${ }^{31,32}$ The reasons for these divergent findings remain unclear but a possible explanation would be that the difference in MPFC activity when contrasting self and close other conditions depends on the perceived similarity or overlap between oneself and close others, which in turn varies across individuals and situations. We will return to this point when discussing the possible function of the MPFC. 


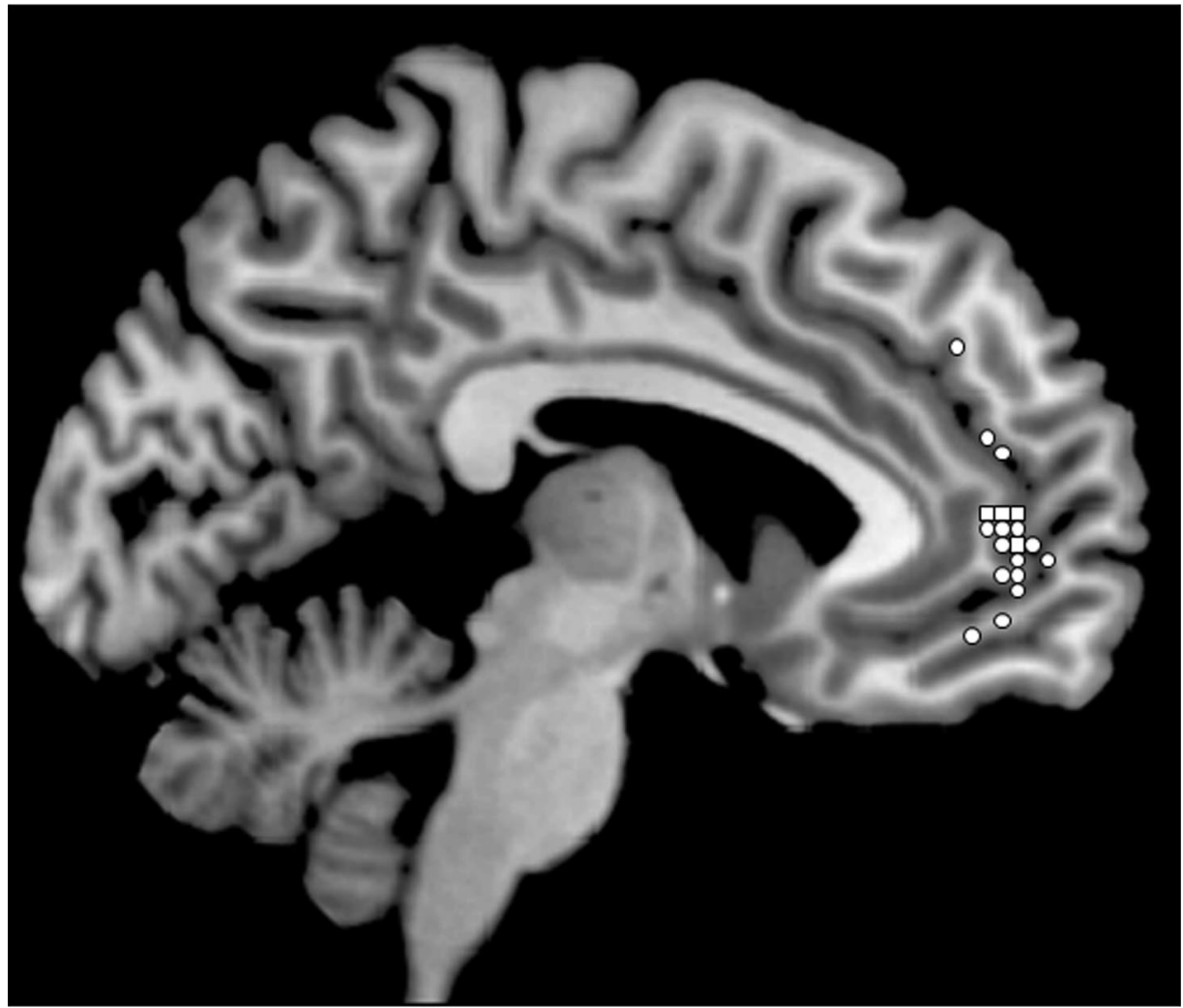

Figure 1. MPFC activations associated with semantic forms of self-knowledge. White circles represent the locations of peak MPFC activations detected when reflecting on one's own psychological traits relative to reflecting on the traits of others or making semantic judgements. ${ }^{13-23,25,26,29,30}$ White squares represent the locations of peak MPFC activations detected when reflecting on one's own promotion goals. ${ }^{38-41}$

The self-concept comprises multiple self-representations. People may hold distinct views of themselves across different contexts (e.g., in different relationships). ${ }^{33}$ Furthermore, an important part of our self-concept concerns our beliefs about how we are seen by others. Although our own beliefs about ourselves and about how we are seen by others reciprocally influence each other, these two types of self-representations do not necessarily match. ${ }^{34}$ In a recent fMRI study, ${ }^{15}$ we investigated whether representing and reflecting on these two types of self-representations recruit similar brain regions. To do so, we adapted the task used by Kelley et al by including four types of judgments. The first two conditions were similar to previous studies and required participants to judge the extent to which trait adjectives described their own personality (e.g., "Are you impatient?") or the personality of a close friend (e.g., "Is Caroline impatient?"). In the other two conditions, participants were asked to estimate how their friend would judge the adjectives, with the target of the judgments again being either the self (e.g., "According to Caroline, are you impatient?") or the other person (e.g., "According to Caroline, is she impatient?"). We found that the MPFC was more activated when making judgments about the self than when making judgments about the other, both 
when participants made judgments from their own perspective and when they made judgments from the perspective of their friend. Interestingly, we also found that patients with Alzheimer disease presented less accurate self-representations than healthy older adults and did not recruit the MPFC when making judgments about themselves (both when making the judgments from their own perspective and from the perspective of their relatives). ${ }^{35}$ These findings thus suggest that the MPFC may play an important role not only in representing and reflecting on our own self-beliefs, but also in thinking about how we are seen by others.

Besides representations of personal traits, the self-concept also includes knowledge about personal goals (i.e., future states of the self that one strives to achieve or avoid), which plays a key role in guiding and motivating behavior. ${ }^{36,37}$ The neural correlates of reflection on personal goals has been recently investigated by Johnson et al. ${ }^{38}$ During $f$ MRI scanning, participants were instructed to think about their hopes and aspirations, about their duties and obligations and about nonself-relevant topics (e.g., polar bear fishing). The results showed that some regions of the MPFC and posterior cingulate/ precuneus were more activated when thinking about personal goals than when thinking about nonself-relevant topics. There were also distinct activations as a function of the type of personal goals considered: A region of MPFC showed greater activation when thinking about hopes and aspirations, whereas a posterior medial region showed greater activation when thinking about duties and obligations. Subsequent studies have detected similar activations in the MPFC when reflecting on personal goals, especially promotion goals (i.e., things the individual would like to achieve) ${ }^{39-41}$ (see the location of squares on Fig. 1).

In summary, since the advent of functional brain imaging techniques, a growing interest has been devoted to the study of the neural correlates of semantic forms of self-knowledge. Current data indicate that representing and reflecting on various kinds of self-knowledge (such as our own beliefs about our psychological traits, our beliefs about how we are seen by others and our personal goals) typically induce greater activity in the MPFC compared to representing and reflecting on other individuals or processing the general (nonpersonal) meaning of the stimuli.

\section{REPRESENTING ONESELF IN TIME: EPISODIC FORMS OF SELF-KNOWLEDGE}

A fascinating achievement of the human mind is its ability to temporarily disengage from the immediate environment to mentally revisit past experiences or imagine future ones. ${ }^{42-44}$ Such "mental time travels" are associated with the subjective feeling of "re-experiencing" the past or "pre-experiencing" the future (e.g., "seeing" in one's mind the location where a past event took place and the persons and objects that were present, remembering what one thought and felt at that time and so forth $)^{45-48}$ and may thus play a key role in providing the individual with a sense of personal continuity through time. ${ }^{44,49}$ Although semantic self-knowledge is represented separately from (and thus can be accessed independently of) episodic memory, ${ }^{12}$ representations of specific past and future experiences can constrain and nourish our beliefs about ourselves ${ }^{50}$ For example, the belief that "I am a shy person" may be fostered by my memory of feeling uncomfortable and behaving awkwardly the last time I met new people at a party. An important function of mental time travel may therefore be to provide "episodic forms of 
self-knowledge", that is, representations of specific personal experiences that support and constrain more abstract representations of the self.

The neural correlates of episodic forms of self-knowledge have been mainly investigated in studies of autobiographical memory (for a review, see refs. 51-53). In many of these studies, participants were asked to recall memories of specific past experiences (i.e., events that were specifically located in place and time and that lasted less than a day) in response to a series of cue words (e.g., vacation, dress). This autobiographical retrieval condition is typically compared to the retrieval of nonpersonal information (e.g., retrieving nonpersonal semantic knowledge or recalling stimuli that have been learned in the laboratory before the scanning session). Recent meta-analyses indicate that autobiographical memory retrieval relies on a specific set of brain regions that includes the MPFC, regions in medial and lateral temporal cortices, the posterior cingulate/retrosplenial cortex and the inferior parietal lobe. ${ }^{54-56}$ Notably, recent studies have shown that similar brain regions are also associated with the imagination of specific future events, ${ }^{57-63}$ suggesting that common processes are involved in representing specific past and future events. ${ }^{42,43}$

Autobiographical memory and future thinking involve multiple component processes, ${ }^{42,43,64,65}$ and it is likely that different processes depend on distinct brain areas within the network described above. In a recent fMRI study, ${ }_{6}^{66}$ we sought to isolate the brain regions that are specifically related to self-referential processes when representing specific future events. We asked participants to imagine future events that were relevant to their personal goals (personal future events; e.g., getting married next summer) and future events that were plausible and could be vividly imagined but were unrelated to their personal goals (nonpersonal future events; e.g., taking a pottery lesson next summer), as determined by individualized prescan interviews. As a control task, participants were asked to imagine routine activities (e.g., taking a shower), which involved the construction of mental representations of complex scenes but lacked the process of projecting oneself into the future. In line with other studies of episodic future thinking, ${ }^{57-63}$ a network of brain regions that included the MPFC, the posterior cingulate cortex (PCC), the inferior parietal lobe and the lateral temporal lobe was more activated when participants imagined personal future events (i.e., future events that were related to their personal goals) than when they imagined routine activities. Our main interest was then to directly contrast the imagination of personal and nonpersonal future events in order to isolate the brain regions that support personal goal processing during episodic future thought. This comparison revealed greater activation in the MPFC and PCC when imaging personal future events relative to nonpersonal future events. Importantly, these two types of future events were matched for vividness and temporal distance, suggesting that differences in brain activation cannot be accounted by these factors alone. The findings thus suggest that the MPFC and PCC may play a specific role in personal goal processing during episodic future thought.

In the same study, we also sought to investigate whether common brain regions were implicated in self-referential processing across different functional domains. To this end, we isolated the brain regions that were associated with semantic forms of self-knowledge in the same participants, using a task that involved making judgments about one's own psychological traits (see the section on the semantic forms of self-knowledge). We then looked at the overlap between brain activations related to this task and brain activations associated with self-referential processing in the episodic 
domain (i.e., imaging personal versus nonpersonal future events). Brain activations associated with the two tasks overlapped in the MPFC and PCC. These findings suggest that semantic and episodic forms of self-knowledge may engage common self-referential processes, which may in part be supported by the MPFC and PCC. In line with this view, a meta-analysis of functional neuroimaging studies has revealed that cortical midline structures (i.e., the MPFC and the PCC/precuneus) were involved in processing self-referential information across multiple cognitive domains and sensory modalities (e.g., the recognition of one's own body and actions, self-face recognition and the representation of one's own traits) ${ }^{67}$

\section{SELF-REFERENTIAL PROCESSING AND THE "DEFAULT NETWORK"}

The brain regions that are most frequently engaged during self-referential tasks (i.e., the MPFC and PCC) are part of the brain's "default network", a network of areas that show decreased activity during a wide range of demanding cognitive tasks relative to passive resting or viewing states. ${ }^{68-71}$ The precise function of the default network remains to be investigated in detail, but an interesting possibility is that this network mediates a number of processes that are ongoing during resting states and attenuated when resources are temporarily re-allocated to the processing of a particular task. ${ }^{72,73}$ The specific processes that are ongoing during resting states are probably manifold (e.g., the monitoring of external environment and body state, autobiographical retrieval, future thinking) and it is likely that different brain areas within the default network are involved in distinct processes.

In a PET study, we sought to investigate whether self-referential processes occur during resting states and to determine whether common brain regions are engaged during resting states and intentional self-reflection. ${ }^{14}$ To this end, scans were acquired while participants were asked to simply relax and not think in a systematic way (rest scans) or to focus their mental activity on specific topics pertaining either to the self (i.e., thinking about one's own traits) or other topics (i.e., thinking about the traits of another person or about social issues). Importantly, subjects' activity during the reflective tasks was exclusively internal (i.e., no stimuli were presented during the scans and no responses were required), so that the reflective and rest scans were closely matched in this respect. Immediately after each scan, subjects were asked to verbally report the thoughts, images, feelings, sensations and memories that they experienced during the scan and they also rated different dimensions of their subjective experience using rating scales (e.g., the amount of self-referential thoughts, the amount of thoughts about other individuals). The data revealed that participants spontaneously experienced a substantial amount of self-referential thoughts during rest scans. We then investigated brain regions that were commonly activated during rest and intentional self-referential processing relative to the other tasks and found common activation in the MPFC. Furthermore, across all conditions, we found that the degree of activity in MPFC correlated with self-reported amount of self-referential thoughts; on the other hand, there was no correlation with the amount of thoughts concerning others. These findings thus suggest that some sort of self-referential processes spontaneously occur during so-called resting conditions and that such processes are associated with MPFC activity. 


\section{A POTENTIAL ROLE OF THE MPFC IN SELF-REFERENTIAL PROCESSING}

As we have seen, activation of the MPFC has been repeatedly observed in association with tasks that require to process information in reference to oneself. There is currently no consensual view, however, regarding the precise nature of the cognitive processes that are supported by this brain region. While it is beyond the scope of this chapter to provide a comprehensive review of the various processes that have been linked to the MPFC, it is important to note that the question of whether or not this brain region plays a specific role in self-referential processing is debated. Some authors have argued that although the MPFC supports processes that are recruited when one is considering information about the self (e.g., when making judgments about one's personal characteristics), the nature of these processes may have nothing to do with the self per se and may instead consist of nonself-specific processes, such as inferential processing and memory retrieval, for example. ${ }^{27,74}$ On the other hand, other researchers have suggested that the MPFC may play some specific role in self-referential processing., ${ }^{8,28,29,67,75,76}$ It has been suggested, in particular, that the MPFC may support supramodal processes that, explicitly or implicitly, appraise and code the self-relatedness or self-relevance of multiple sources of information. ${ }^{8,67,76}$ According to this view, the MPFC may mediate dynamic processes that locate external stimuli and internal representations on a continuum of personal relevance. In line with this hypothesis, there is evidence that activity in the MPFC increases linearly with increased ratings of self-relevance of stimuli. ${ }^{75,77} \mathrm{~A}$ recent study by Moran et al ${ }^{78}$ further suggests that the MPFC signals the personal relevance of incoming information even in the absence of explicit requirements for self-reflection (i.e., during passive viewing conditions).

We have recently speculated that by processing degrees of self-relevance or self-relatedness, the MPFC might sustain the process of identifying oneself with versus distancing oneself from particular mental contents (e.g., thoughts, opinions, preferences), which would therefore be regarded as "me" (or "mine") versus "not-me" (or "not-mine"). ${ }^{29}$ The MPFC might thus contribute to the great splitting of the universe made by each of us that William James referred to more than a century ago. ${ }^{1}$ Of course, we agree that the creation of our sense of self involves multiple nonself-specific processes, such as memory and reasoning processes. ${ }^{27,74}$ These nonself-specific processes rely on multiple brain regions, including medial and lateral temporal cortices, the posterior cingulate cortex and the lateral prefrontal cortex, which are involved in acquiring, retrieving and using information (whether it be about the self, others or the world). Our suggestion, however, is that the MPFC might play a role in processing the self-relatedness or self-relevance of information that is represented in other "high-level" or "low-level" brain regions. Representations that elicit high activity in the MPFC might be those that constitute the mental model of the self that is displayed in our mind at a given moment ("the working self"). ${ }^{10}$ In this section, we discuss evidence that we think supports this hypothesis.

If the MPFC is involved in processing self-relevance or self-relatedness, then factors that diminish the perceived degree of self-relatedness of information should modulate neural activity in the MPFC accordingly. Recent studies that have examined the effects of temporal perspective on the neural correlates of self-referential processing suggest that this is indeed the case. Some philosophers have suggested that a person is a succession 

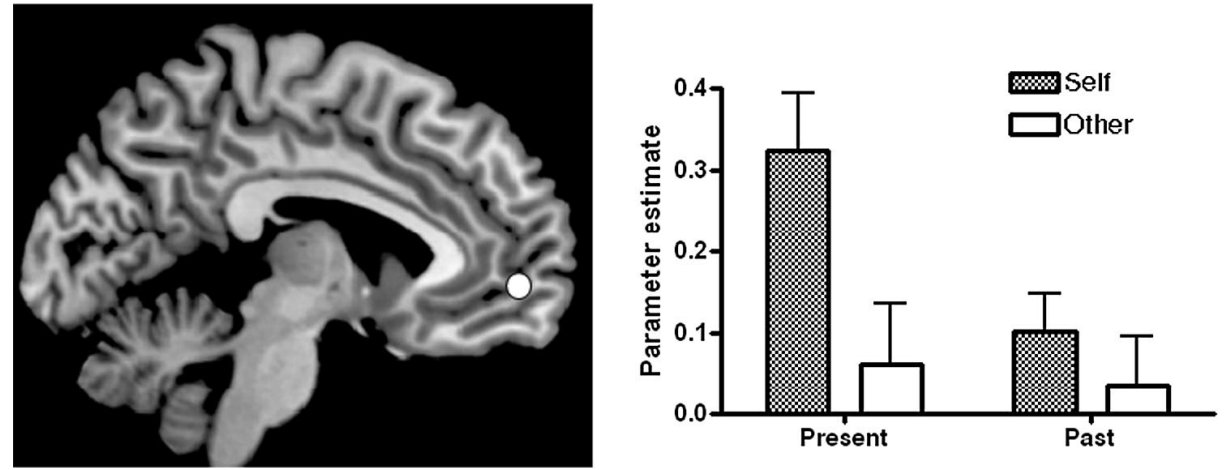

Figure 2. The effect of temporal perspective on MPFC activity when thinking about oneself and others. The left panel shows a region of MPFC in which activity was modulated by adopting different temporal perspectives on the self and others. As can be seen on the right panel, the MPFC was recruited to a greater extent when reflecting on the present self than when reflecting on the past self and when reflecting on the other person; thinking about the past self and thinking about the other person were associated with similar levels of activity. Adapted from reference 29.

of overlapping but different selves ${ }^{79}$ and research in social psychology has revealed that when people feel they have changed, they tend to distance themselves from psychologically remote former selves, which are then regarded as "other persons". ${ }^{80-82}$ Someone may, for example, have a mental model of who she was five years ago (e.g., knowing that she was shy) but may no longer identify herself with that model. Although she can recognize that the person to whom the mental model refers to was herself, she no longer identifies that model as "me" (i.e., her current self) because she feels she has changed (e.g., she feels she is not shy anymore). We recently found that activity in the MPFC is sensitive to these effects of temporal perspective. ${ }^{29}$ Specifically, we asked participants to reflect on their own psychological traits and those of an intimate other, for both the present life period (i.e., at college) and a past life period (i.e., high school years) that involved significant personal changes. The MPFC was commonly recruited by the four reflective tasks (reflecting on the present self, past self, present other and past other), relative to a control condition (making valence judgments), suggesting that this brain region may play a general role in reflecting on mental states and psychological characteristics. ${ }^{83}$ Importantly, however, the degree of activity in MPFC also varied significantly according to the target of reflection, this region being recruited to a greater extent when reflecting on the present self than when reflecting on the past self and when reflecting on the other person; thinking about the past self and thinking about the other person were associated with similar levels of activity in the MPFC (see Fig. 2). This study thus demonstrates that increasing the psychological distance of self-representations leads to diminished activity in the MPFC, such that the degree of activity associated with thinking about oneself is similar to the degree of activity associated with thinking about others.

In a subsequent study, ${ }^{84}$ we replicated and extended these findings, by showing that differences in MPFC activity when thinking about current versus temporally distant selves are symmetrical between the past and the future. Specifically, participants showed higher activity in the MPFC when making judgments about their present self than when making judgments about themselves five years ago or five years from now; there was no difference between past and future selves. Importantly, these findings could not simply 
be accounted for in terms of task difficulty or memory retrieval, suggesting that the critical factor that underlies the effects of temporal perspective on MPFC activity relates to feelings of connectedness to self-representations. Research has further showed that individual differences in perceived connectedness to future selves and its neural signature (i.e., MPFC activity) hold important implications for decision making, such as choosing whether to save for the future or spend in the present. ${ }^{85,86}$

Other studies suggest that the degree of MPFC activity when thinking about others depends on the perceived similarity or degree of overlap between oneself and the other person under consideration. As we have seen, although judgments about oneself versus a nonclose other have been repeatedly associated with greater activation in MPFC, the studies that have directly compared judgments about the self versus a close other have provided mixed results (see the section on semantic forms of self-knowledge). These findings can be seen as supporting the view that the MPFC is not involved in self-referential processing per se but instead supports nonself-specific processes (e.g., familiarity processing, memory retrieval), which would be engaged to different extents when making judgments about oneself, close others and nonclose others. ${ }^{27,74}$ The modulation of MPFC activity as a function of closeness with others can be interpreted differently, however. As already noted by William James, ${ }^{1}$ people's identities include not only elements that are unambiguously part of them (e.g., their body and mental states) but also outer aspects of their lives, such as their family, friends and possessions. Extensive research has indeed shown that people treat the resources, perspectives and identities of close others as their own (think, for example, about how you react when a loved one is mistreated) and these effects depend on the degree to which the individual has included the other person in the self. ${ }^{87}$ The fact that the magnitude of activation in the MPFC is more similar between the self and close others than between the self and nonclose others may thus reflect differences in degrees of inclusion of others in the sense of self.

Recent studies that have explored cultural differences in the neural correlates of self-referential processing are consistent with this interpretation. East Asian cultures promote collectivistic self-views more than Western cultures, emphasizing the interconnectedness rather than separateness between the self and close others. ${ }^{88} \mathrm{Zhu}$ et al measured brain activity using fMRI while Western and Chinese participants judged trait adjectives in reference to the self, their mother or a public person..$^{30}$ The results showed that the MPFC was more activated in the self condition than in the public person condition for both Western and Chinese participants. The comparison between mother and public figure differed between groups, however, with MPFC being more activated for the close versus public other in Chinese but not Western subjects. Furthermore, Western participants showed increased activations in the MPFC when thinking about the self versus their mother, whereas there was no difference between self and mother in Chinese participants. This study therefore demonstrates that differences in MPFC activity between self and a close other is modulated by cultural differences in the degree of inclusion of intimate others in the sense of self.

There is also evidence that inferring the mental states of unfamiliar individuals that are perceived as similar to the self engages the MPFC more than inferring the mental states of unfamiliar individuals that are perceived as dissimilar..$^{19,89,90}$ For example, Mitchell et a ${ }^{90}$ had participants read descriptions of an unfamiliar individual whose social and political views were similar to their own views and descriptions of another unfamiliar individual whose social and political views were dissimilar. Then, during fMRI scanning, participants had to infer the opinions, likes and dislikes of these two target persons. The results showed that the 
ventral MPFC was more engaged during judgments of the individual who was perceived as similar to the self than during judgments of the individual who was perceived as dissimilar. Furthermore, correlation analyses revealed that the more participants considered themselves similar to the "similar" other, the greater the difference in ventral MPFC activation during judgments of similar versus dissimilar other. These findings clearly demonstrate that the extent to which the MPFC is engaged when thinking about others depends on the degree of perceived similarity of the other person to oneself.

According to the view defended here, the MPFC may not be involved in making fixed and rigid self/nonself distinctions, but may instead mediate dynamic processes that locate information on a continuum of self-relevance or self-relatedness. The distinction between self and nonself may thus be a matter of degree and what is regarded as the "self" may vary across time and situations, depending on what information one identifies with at a given moment (i.e., what one includes in the currently activated self-concept)..$^{10}$ This hypothesis predicts that, depending on contextual factors, the same information could be included in versus excluded from the current mental model of the self and this should be reflected in MPFC activity.

A recent study suggests that this is indeed the case, showing that priming cultural values of individualism versus collectivism in bicultural individuals induces increased activity in the MPFC for culturally congruent self-judgments. ${ }^{91}$ Behavioral studies have shown that people of individualistic cultures tend to think about themselves using general self-descriptions (e.g., I am honest), whereas people from collectivistic cultures tend to think about themselves using more contextual self-descriptions (e.g., when talking to my mother, I am honest). Research has also shown that when primed to orient more toward either an individualistic or collectivistic schema, people will think about themselves in a way that is consistent with the cultural schema temporarily brought to mind. Chiao et al ${ }^{91}$ investigated whether neural activity when making self-referential judgments would be influenced by such cultural priming. Participants were Asian-Americans living in the United States who identified themselves as bicultural as assessed by a questionnaire. They were asked to make judgments about general self-descriptions, contextual self-descriptions and a control task (judgments about font style). Before doing those tasks, half of the participants received priming procedures designed to activate individualistic cultural schemas (e.g., thinking about what make them different from their family and friends), whereas the other half received priming procedures designed to activate collectivistic cultural schemas (e.g., thinking about what they have in common with their family and friends). The authors found a significant interaction between priming conditions and types of self-judgments in the MPFC. Specifically, participants primed with individualism showed greater activation in the MPFC for general relative to contextual self-descriptions, whereas individuals primed with collectivism showed greater activation in the same regions for contextual relative to general self-descriptions. Furthermore, across all participants, the degree of cultural priming of individualistic or collectivistic values was associated with the degree of MPFC response to general or contextual self-descriptions, respectively. This study thus suggests that the response of the MPFC to a particular self-description depends on whether or not this information is congruent with the self-concept activated at a given moment.

In summary, recent functional neuroimaging studies have shown that a) the degree of activity in the MPFC when thinking about oneself diminishes when the psychological distance of self-representations increases, $b$ ) the degree of activity in the MPFC when thinking about others depends on the extent to which the other person is included in one's sense of self and c) the response of the MPFC to particular self-definitions depends 
on whether or not these definitions are congruent with temporarily activated cultural values. Overall, these findings are consistent with the hypothesis that the MPFC may mediate dynamic processes that locate information on a continuum of self-relevance or self-relatedness. Information that is located at the upper end of this continuum may be incorporated in the mental model of the self that is displayed in our mind at a given moment, thereby being subjectively considered to be part of "me" or "mine".

\section{CONCLUSION}

Throughout evolution, hominids have developed greater capacity to think about the self in abstract and symbolic ways. This process has reached its apex in humans with the construction of a concept of oneself as a distinct entity with a personal history. Humans are able to consciously represent and reflect on their own personal attributes (e.g., their abilities, social roles, psychological characteristics and preferences) and frequently engage in mental time travels to mentally revisit their past experiences or imagine future ones. Recent studies that have used functional neuroimaging techniques to investigate the neural correlates of these self-referential processes point to the MPFC as a critical neural structure for processing both semantic and episodic forms of self-knowledge. A key function of this brain region may be to appraise and code the self-relatedness or self-relevance of information. Mental representations (e.g., traits, opinions, preferences, experiences) may be located on a continuum of self-relatedness, depending on the degree of activity they elicit in MPFC. Information that is located at the upper end of this continuum may be incorporated in the mental model of the self that is currently displayed in our mind, thereby being subjectively considered as "me" or "mine". The MPFC may thus implement dynamic neural processes that contribute to the division of the world into "me" and "not-me" that each of us subjectively experience. Recent studies that have examined the effects of cultural values and temporal perspectives on the neural correlates of self-referential processing are consistent with this proposal. The neuroscience of self-referential processing is still in its infancy, however, and additional investigations are needed to develop a full understanding of this aspect of human experience.

\section{ACKNOWLEDGMENTS}

Arnaud D'Argembeau is supported by the Fund for Scientific Research(F.R.S.-FNRS), Belgium. This work was supported by a grant from the French-speaking community of Belgium (ARC, Convention 06/11-340).

\section{REFERENCES}

1. James W. The Principles of Psychology. New York: Holt, 1890.

2. Bongard J, Zykov V, Lipson H. Resilient machines through continuous self-modeling. Science 2006; 314:1118-1121.

3. Legrand D. Subjectivity and the body: introducing basic forms of self-consciousness. Conscious Cogn 2007; 16:577-582.

4. Gallagher S. Philosophical conceptions of the self: implications for cognitive sciences. Trends Cogn Sci $2000 ; 4: 14-21$. 
5. Damasio AR. The feeling of what happens: body and emotion in the making of consciousness. New York: Harcourt Brace, 1999.

6. Neisser U. Five kinds of self-knowledge. Philos Psychol 1988; 1:35-59.

7. Lieberman MD. Social cognitive neuroscience: a review of core processes. Annu Rev Psychol 2007; 58:259-289.

8. Northoff G, Bermpohl F. Cortical midline structures and the self. Trends Cogn Sci 2004; 8:102-107.

9. Leary MR, Buttermore NR. The evolution of the human self: tracing the natural history of self-awareness. J Theory Soc Behav 2003; 33:365-404.

10. Markus H, Wurf E. The dynamic self-concept: a social psychological perspective. Annu Rev Psychol 1987; 38:299-337.

11. Klein SB, Robertson TE, Gangi CE et al. The functional independence of trait self-knowledge: commentary on Sakaki (2007). Memory 2008; 16:556-565.

12. Klein SB, Rozendal K, Cosmides L. A social-cognitive neuroscience analysis of the self. Soc Cogn 2002; 20:105-135.

13. Kelley WM, Macrae CN, Wyland CL et al. Finding the self? An event-related fMRI study. J Cogn Neurosci 2002; 14:785-794.

14. D'Argembeau A, Collette F, Van der Linden M et al. Self-referential reflective activity and its relationship with rest: a PET study. Neuroimage 2005; 25:616-624.

15. D'Argembeau A, Ruby P, Collette F et al. Distinct regions of the medial prefrontal cortex are associated with self-referential processing and perspective taking. J Cogn Neurosci 2007; 19:935-944.

16. Eddington KM, Dolcos F, Cabeza R et al. Neural correlates of promotion and prevention goal activation: an fMRI study using an idiographic approach. J Cogn Neurosci 2007; 19:1152-1162.

17. Fossati P, Hevenor SJ, Graham SJ et al. In search of the emotional self: an fMRI study using positive and negative emotional words. Am J Psychiatry 2003; 160:1938-1945.

18. Gutchess AH, Kensinger EA, Schacter DL. Aging, self-referencing and medial prefrontal cortex. Soc Neurosci 2007; 2:117-133.

19. Jenkins AC, Macrae CN, Mitchell JP. Repetition suppression of ventromedial prefrontal activity during judgments of self and others. Proc Natl Acad Sci USA 2008; 105:4507-4512.

20. Johnson SC, Baxter LC, Wilder LS et al. Neural correlates of self-reflection. Brain 2002; 125:1808-1814.

21. Lemogne C, le Bastard G, Mayberg H et al. In search of the depressive self: extended medial prefrontal network during self-referential processing in major depression. Soc Cogn Affect Neurosci 2009; 4:305-312.

22. Lombardo MV, Chakrabarti B, Bullmore ET et al. Shared neural circuits for mentalizing about the self and others. J Cogn Neurosci 2010; 22(7):1623-35.

23. Pfeifer JH, Lieberman MD, Dapretto M. "I know you are but what am I?!": neural bases of self- and social knowledge retrieval in children and adults. J Cogn Neurosci 2007; 19:1323-1337.

24. Saxe R, Moran JM, Scholz J et al. Overlapping and non-overlapping brain regions for theory of mind and self relfection in individual subjects. Soc Cogn Affect Neurosci 2006; 1:229-234.

25. Schmitz TW, Kawahara-Baccus TN, Johnson SC. Metacognitive evaluation, self-relevance and the right prefrontal cortex. Neuroimage 2004; 22:941-947.

26. Yoshimura S, Ueda K, Suzuki S et al. Self-referential processing of negative stimuli within the ventral anterior cingulate gyrus and right amygdala. Brain Cogn 2009; 69:218-225.

27. Gillihan SJ, Farah MJ. Is self special? A critical review of evidence from experimental psychology and cognitive neuroscience. Psychol Bull 2005; 131:76-97.

28. Heatherton TF, Wyland CL, Macrae CN et al. Medial prefrontal activity differentiates self from close others. Soc Cogn Affect Neurosci 2006; 1:18-25.

29. D'Argembeau A, Feyers D, Majerus S et al. Self-reflection across time: cortical midline structures differentiate between present and past selves. Soc Cogn Affect Neurosci 2008; 3:244-252.

30. Zhu Y, Zhang L, Fan J et al. Neural basis of cultural influence on self-representation. Neuroimage 2007; 34:1310-1316.

31. Ochsner KN, Beer JS, Robertson ER et al. The neural correlates of direct and reflected self-knowledge. Neuroimage 2005; 28:797-814.

32. Vanderwal T, Hunyadi E, Grupe DW et al. Self, mother and abstract other: an fMRI study of reflective social processing. Neuroimage 2008; 41:1437-1446.

33. Chen S, Boucher HC, Tapias MP. The relational self revealed: integrative conceptualization and implications for interpersonal life. Psychol Bull 2006; 132:151-179.

34. Tice DM, Wallace HM, Leary MR et al. The reflected self: creating yourself as (you think) others see you. Handbook of Self and Identity. New York, NY: Guilford Press, 2003:91-105.

35. Ruby P, Collette F, D'Argembeau A et al. Perspective taking to assess self-personality: what's modified in Alzheimer's disease? Neurobiol Aging 2009; 30:1637-1651.

36. Higgins ET. Beyond pleasure and pain. Am Psychol 1997; 52:1280-1300.

37. Markus H, Nurius P. Possible selves. Am Psychol 1986; 41:954-969. 
38. Johnson MK, Raye CL, Mitchell KJ et al. Dissociating medial frontal and posterior cingulate activity during self-reflection. Soc Cogn Affect Neurosci 2006; 1:56-64.

39. Johnson MK, Nolen-Hoeksema S, Mitchell KJ et al. Medial cortex activity, self-reflection and depression. Soc Cogn Affect Neurosci 2009; 4(4):313-27.

40. Mitchell KJ, Raye CL, Ebner NC et al. Age-group differences in medial cortex activity associated with thinking about self-relevant agendas. Psychol Aging 2009; 24:438-449.

41. Packer DJ, Cunningham WA. Neural correlates of reflection on goal states: the role of regulatory focus and temporal distance. Soc Neurosci 2009; 4:412-425.

42. Schacter DL, Addis DR, Buckner RL. episodic simulation of future events: concepts, data and applications. Ann N Y Acad Sci 2008; 1124:39-60.

43. Suddendorf T, Corballis MC. The evolution of foresight: what is mental time travel and is it unique to humans? Behav Brain Sci 2007; 30:299-351.

44. Tulving E. Episodic memory and autonoesis: uniquely human? In: Terrace HS, Metcalfe J, eds. The Missing Link in Cognition: Origins of Self-reflective Consciousness. Oxford: Oxford University Press, 2005:3-56.

45. D'Argembeau A, Van der Linden M. Phenomenal characteristics associated with projecting oneself back into the past and forward into the future: influence of valence and temporal distance. Conscious Cogn 2004; 13:844-858.

46. D'Argembeau A, Van der Linden M. Individual differences in the phenomenology of mental time travel: the effect of vivid visual imagery and emotion regulation strategies. Conscious Cogn 2006; 15:342-350.

47. Rubin DC, Schrauf RW, Greenberg DL. Belief and recollection of autobiographical memories. Mem Cognit 2003; 31:887-901.

48. Szpunar KK, McDermott KB. Episodic future thought and its relation to remembering: evidence from ratings of subjective experience. Conscious Cogn 2008; 17:330-334.

49. Klein SB, Loftus J, Kihlstrom JF. Memory and temporal experience: the effects of episodic memory loss on an amnesic patient's ability to remember the past and imagine the future. Soc Cogn 2002; 20:353-379.

50. Conway MA. Memory and the self. J Mem Lang 2005; 53:594-628.

51. Cabeza R, St Jacques P. Functional neuroimaging of autobiographical memory. Trends Cogn Sci 2007; 11:219-227.

52. Maguire EA. Neuroimaging studies of autobiographical event memory. Philos T R Soc B 2001;356:1441-1451.

53. Piolino P, Desgranges B, Eustache F. Episodic autobiographical memories over the course of time: cognitive, neuropsychological and neuroimaging findings. Neuropsychologia 2009; 47:2314-2329.

54. McDermott KB, Szpunar KK, Christ SE. Laboratory-based and autobiographical retrieval tasks differ substantially in their neural substrates. Neuropsychologia 2009; 47:2290-2298.

55. Spreng RN, Mar RA, Kim AS. The common neural basis of autobiographical memory, prospection, navigation, theory of mind and the default mode: a quantitative meta-analysis. J Cogn Neurosci 2008; 21:489-510.

56. Svoboda E, McKinnon MC, Levine B. The functional neuroanatomy of autobiographical memory: a meta-analysis. Neuropsychologia 2006; 44:2189-2208.

57. Addis DR, Wong AT, Schacter DL. Remembering the past and imagining the future: common and distinct neural substrates during event construction and elaboration. Neuropsychologia 2007; 45:1363-1377.

58. Botzung A, Denkova E, Manning L. Experiencing past and future personal events: functional neuroimaging evidence on the neural bases of mental time travel. Brain Cogn 2008; 66:202-212.

59. D'Argembeau A, Xue G, Lu ZL et al. Neural correlates of envisioning emotional events in the near and far future. Neuroimage 2008; 40:398-407.

60. Okuda J, Fujii T, Ohtake H et al. Thinking of the future and past: the roles of the frontal pole and the medial temporal lobes. Neuroimage 2003; 19:1369-1380.

61. Sharot T, Riccardi AM, Raio CM et al. Neural mechanisms mediating optimism bias. Nature 2007; 450:102-105.

62. Spreng RN, Grady CL. Patterns of brain activity supporting autobiographical memory, prospection and theory-of-mind and their relationship to the default mode network. J Cogn Neurosci 2010; 22:1112-1223.

63. Szpunar KK, Watson JM, McDermott KB. Neural substrates of envisioning the future. Proc Natl Acad Sci USA 2007; 104:642-647.

64. Hassabis D, Maguire EA. Deconstructing episodic memory with construction. Trends Cogn Sci 2007; 11:299-306.

65. Rubin DC. The basic-systems model of episodic memory. Perspect Psychol Sci 2006; 1:277-311.

66. D'Argembeau A, Stawarczyk D, Majerus S et al. The neural basis of personal goal processing when envisioning future events. J Cogn Neurosci 2010; 22:1701-13.

67. Northoff G, Heinzel A, de GM et al. Self-referential processing in our brain - a meta-analysis of imaging studies on the self. Neuroimage 2006; 31:440-457.

68. Binder JR, Frost JA, Hammeke TA et al. Conceptual processing during the conscious resting state: a functional MRI study. J Cogn Neurosci 1999; 11:80-93. 
69. Mazoyer B, Zago L, Mellet E et al. Cortical networks for working memory and executive functions sustain the conscious resting state in man. Brain Res Bull 2001; 54:287-298.

70. Shulman GL, Fiez JA, Corbetta $\mathrm{M}$ et al. Common blood flow changes across visual tasks II: decreases in cerebral cortex. J Cogn Neurosci 1997; 9:648-663.

71. Wicker B, Ruby P, Royet JP et al. A relation between rest and the self in the brain? Brain Res Brain Res Rev 2003; 43:224-230.

72. Buckner RL, Andrews-Hanna JR, Schacter DL. The brain's default network-anatomy, function and relevance to disease. Ann NY Acad Sci 2008; 1124:1-38.

73. Gusnard DA, Raichle ME. Searching for a baseline: functional imaging and the resting human brain. Nat Rev Neurosci 2001; 2:685-694.

74. Legrand D, Ruby P. What is self-specific? Theoretical investigation and critical review of neuroimaging results. Psychol Rev 2009; 116:252-282.

75. Moran JM, Macrae CN, Heatherton TF et al. Neuroanatomical evidence for distinct cognitive and affective components of self. J Cogn Neurosci 2006; 18:1586-1594.

76. Schmitz TW, Johnson SC. Relevance to self: a brief review and framework of neural systems underlying appraisal. Neurosci Biobehav Rev 2007; 31:585-596.

77. Phan KL, Taylor SF, Welsh RC et al. Neural correlates of individual ratings of emotional salience: a trial-related fMRI study. Neuroimage 2004; 21:768-780.

78. Moran JM, Heatherton TF, Kelley WM. Modulation of cortical midline structures by implicit and explicit self-relevance evaluation. Soc Neurosci. 2009; 4:197-211.

79. Parfit D. Personal identity. Philosophical Review 1971; 80:3-27.

80. Libby LK, Eibach RP. Looking back in time: self-concept change affects visual perspective in autobiographical memory. J Pers Soc Psychol 2002; 82:167-179.

81. Pronin E, Ross L. Temporal differences in trait self-ascription: when the self is seen as an other. J Pers Soc Psychol 2006; 90:197-209.

82. Wilson AE, Ross M. The identity function of autobiographical memory: time is on our side. Memory 2003; 11:137-149.

83. Amodio DM, Frith CD. Meeting of minds: the medial frontal cortex and social cognition. Nat Rev Neurosci 2006; 7:268-277.

84. D'Argembeau A, Stawarczyk D, Majerus S et al. Modulation of medial prefrontal and inferior parietal cortices when thinking about past, present and future selves. Soc Neurosci 2010; 5:187-200.

85. Ersner-Hershfield H, Garton MT, Ballard Ket al. Don't stop thinking about tomorrow: individual differences in future self-continuity account for saving. Judgm Decis Mak 2009; 4:280-286.

86. Ersner-Hershfield H, Wimmer GE, Knutson B. Saving for the future self: neural measures of future self-continuity predict temporal discounting. Soc Cogn Affect Neurosci 2009; 4:85-92.

87. Aron A, McLaughlin-Volpe T, Mashek D et al. Including others in the self. European Review of Social Psychology 2004; 15:101-132.

88. Markus HR, Kitayama S. Culture and the self: implications for cognition, emotion and motivation. Psychol Rev 1991; 98:224-253.

89. Mitchell JP, Banaji MR, Macrae CN. The link between social cognition and self-referential thought in the medial prefrontal cortex. J Cogn Neurosci 2005; 17:1306-1315.

90. Mitchell JP, Macrae CN, Banaji MR. Dissociable medial prefrontal contributions to judgments of similar and dissimilar others. Neuron 2006; 50:655-663.

91. Chiao JY, Harada T, Komeda H et al. Dynamic cultural influences on neural representations of the self. J Cogn Neurosci 2010; 22:1-11. 